\title{
Two-Way but Asymmetrical Reproductive Interference between an Invasive Veronica Species and a Native Congener
}

\author{
Koh-Ichi Takakura \\ Group of Urban Environment, Osaka City Institute of Public Health and Environmental Sciences, Osaka, Japan. \\ Email: takakura@nature.email.ne.jp
}

Received January $10^{\text {th }}, 2013$; revised February $14^{\text {th }}, 2013$; accepted February $26^{\text {th }}, 2013$

\begin{abstract}
Recent studies have suggested that reproductive interference, a deleterious interspecific interaction in the mating process, plays an important role in biological invasions. In the system of plant species, however, the border with the pollen limitation has often been vague in past studies. This study, using field and laboratory experiments and field observations, examined the reproductive success of an endangered native herbaceous plant, Veronica polita lilacina, in the context of the reproductive interference by the alien congener, $V$. persica. The auto-pollination experiment confirmed that both species can usually produce seeds even without external conspecific pollens. Results of the artificial pollination experiment demonstrated that pollination with the heterospecific pollens significantly decreases the number of seeds in the native species, but not in the alien species. A transplant experiment revealed that the coexistence with the alien species reduced the fruiting success of the native species. Field observations have shown the interaction between two species in the native patch with only one intruding alien species. They demonstrated that native individuals placed closer to the alien individual suffered a greater decrease in fruiting success and the seed production and that the alien intruder produced no seed. These results demonstrate that species that could reproduce via the auto-pollination suffered the reproductive interference and that the native species also exert the resistive reproductive interference slightly. These interactions can explain the displacement pattern of the native species by the alien congener in Japan.
\end{abstract}

Keywords: Endangered Species; Fruiting Success; Interspecific Pollen Transfer; Veronica persica; Veronica polita lilacina

\section{Introduction}

Ecologists have reported the phenomenon by which invasive alien species often eliminate native species in animals [e.g. 1-3] and plants [e.g. 4-6]. In recent years, as a mechanism of such displacements, reproductive interference has been hypothesized and tested in some animal and plant species [7-9]. Reproductive interference refers to any interspecific interaction that engenders the loss of the reproductive success in either or both interacting species. In plants, for example, heterospecific pollens have been known to interfere with ordinary insemination by conspecific pollens [10-12]. This is an extremely common mechanism affecting reproductive interference in plants.

The pioneer theoretical study [13] that emphasized the ecological significance of reproductive interference included the inference that the interfering effect was evenly reciprocal. If that is the case, then species with larger initial abundance must necessarily outcompete less abun- dant species. Therefore, no room exists for the introduced species to establish new populations. However, enormous numbers of alien species are known to create severe problems worldwide. Increasingly results of numerous empirical studies have also suggested that reproductive interference is biased or rather one-way $[8,9$, 14-17]. The extent of the bias of the reproductive interference between the alien and native species might provide a key to explaining the invasion speed of alien species. Resistive reproductive interference from the native to alien species might delay the invasion. However, although it has been recognized that reproductive interfereence plays a crucial role in biological invasion, the possibility has not been explored adequately $[8,9]$.

As a plant-specific problem, reproductive interference has tended to be confused with pollen limitation. For circumstances in which heterospecific pollen transfer and then reproductive interference can occur, competition for pollinators can also occur. The direct cause of the former is the existence of heterospecific pollens. That of the 
latter is the absence of conspecific pollens. Nevertheless, it is difficult to distinguish them based on field observations alone. Indeed, the reproductive interference that occurs among Taraxacum species $[8,9]$ has been regarded as competition for pollinators [18]. For self-incompatible plants particularly, external conspecific pollens are obligate for seed production and competition for pollinators can be a severe problem. Studies of selfcompatible plants must be undertaken to illustrate the ecological significance of reproductive interference in plants.

A native herbaceous plant, V. polita Fries subsp. lilacina (Yamazaki), has been a quite rare species at the present day. In some of the oldest reports of fauna in Japan, however, Makino [19,20] described this species as a common weed. On the other hand, the alien congeneric species, Veronica persica Poiret, is quite common throughout Japan to the present day. The predominance of the alien species is clear, but the native species remains in some limited regions, although at low density [21]. Consequently, the displacement of the native by the alien Veronica in Japan seems incomplete. Studies of reproductive interference in such species with a pair showing incomplete displacement must be useful to assess the relation between the intensity of the reproductive interference and the alien species invasiveness. In addition, preliminary observations suggested that these species are self-compatible. This point can also be beneficial for studying the reproductive interference for these species pairs.

In this study, first, the auto-pollination and the selfcompatibility of these two Veronica species were confirmed with artificial pollination. Subsequently, the reproductive interference between the two species was examined in two experiments and an observation. First, the native species were transplanted near the alien patches to evaluate the decrease in reproductive success. Second, the heterospecific pollens were attached artificially to stigmas for both species to observe the subsequent seed production. Third, the interaction was observed directly in the frontline of the invasion by the alien species. Based on results of these experiments and observations, the intensity, symmetry, and the ecological significance of reproductive interference between the two Veronica species were discussed.

\section{Materials and Methods}

\subsection{Study Species}

This study examined the relationship between two $V e-$ ronica species, native $V$. p. lilacina and alien $V$. persica. The former species is an endemic to Japan and distributed in almost the whole of Japan in the past. It has been reported to be common at roadsides, cultivated fields and waste lands a century ago $[19,20]$. However, the common Veronica species at such habitats in the present day is the latter alien species. The past literature [22] suggested that this alien species had been introduced approximately a century ago from the present day and that it displaced quickly the native species.

Currently, the coexistence of these two species is rarely observed in the field. It is because the $V$. persica has almost completely displaced $V$. p. lilacina and the latter species has been quite rare at most regions in Japan. The native species has been listed as an endangered species in the Red Data Book [23]. However, the interaction between these two species must have existed in the process that the alien species displaced the native congener because their habitats mostly overlap; roadsides, cultivated fields and waste lands. Furthermore, the structures of flowers of them are similarly simple (Figure 1) and the flowering seasons also overlap. The alien species, $V$. persica, flowers from March to April in the northern hemisphere $[24,25]$. The native $V$. $p$. lilacina also flowers in the same season [25]. There seems no barrier to prevent interspecific pollinations between them. If they sympatrically coexisted, the reproductive interference via interspecific pollinations could occur.

\subsection{Origin of Individuals Used in Experiments}

For transplantation and the artificial pollination experiments, individuals of $V$. p. lilacina that had originated from Hiroshima Pref. were used. Details of the locality will not be reported here in the interest of conserving the rare native species. Seeds were collected on 11 May 2007. They were put on soil in plastic pots $(75 \mathrm{~mm}$ diameter, $75 \mathrm{~mm}$ depth) in July 2008. These pots were put in the laboratory yard of Osaka City Institute of Public Health and Environmental Sciences, Osaka Pref., Japan $\left(34^{\circ} 39^{\prime} 47^{\prime \prime} \mathrm{N}, 135^{\circ} 31^{\prime} 42^{\prime \prime} \mathrm{E}\right)$ and were irrigated arbitrarily.

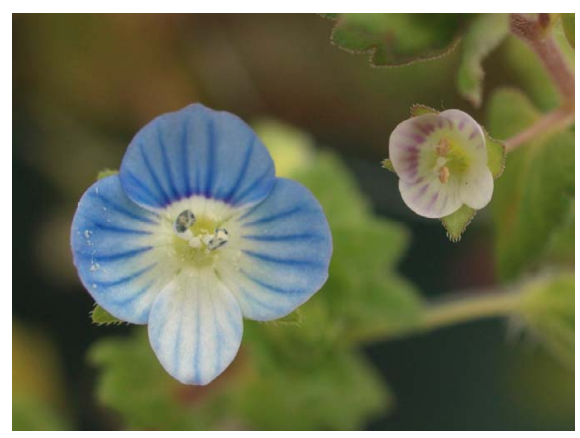

Figure 1. Morphologies of flowers of alien $V$. persica (left) and $V . p$. lilacina (right). This photo was taken in the laboratory yard where these species were artificially planted and such a sympatric coexistence can not be observed at the field in the present day. 
Individuals that flowered in April 2009 were used in experiments.

In the artificial pollination experiment, potted individuals of $V$. persica were also used. These alien individuals were collected in March 2009 at Takatsuki, Osaka Pref., Japan (34 $\left.51^{\prime} 52^{\prime \prime} \mathrm{N}, 135^{\circ} 35^{\prime} 35^{\prime \prime} \mathrm{E}\right)$ and were planted individually in plastic pots $(75 \mathrm{~mm}$ diameter, 75 $\mathrm{mm}$ depth). They were put in the same yard as the pots of natives.

\subsection{Auto-Pollination and Self-Compatibility}

This experiment was conducted to confirm that these two Veronica species can produce seeds even without the pollen exchange with other individuals. The seed numbers were compared between those of flowers that had been artificially pollinated from other conspecific individuals and flowers with no added external pollen. These manipulations were applied to both species. Ten and nine individuals of $V . p$. lilacina and V. persica were used respectively for this experiment. Each flower was assigned arbitrarily to either the cross-pollination or autopollination group. For the cross-pollination group, flowers were pollinated with pollens from other conspecific individuals. The stigma was softly touched with the open anthers of the other conspecific individual. This manipulation was made from 9:00 to 10:00 once for each flower because flowers of these two species of Veronica opened at early morning and fell until noon. Before and after pollination, individuals were covered with fine mesh to prevent the un-intended access of pollinators. For the auto-pollination group, the pollination was not done and individuals were covered while flowers were open. When fruits swelled up, each fruit was covered with a small paper bag to prevent seeds from falling down with the dehiscence of fruits. Two weeks after the pollination, fruits were cropped and the seeds were counted.

\subsection{Transplanting Experiment}

For this experiment, the situation of coexistence of the native and alien species was created artificially because the native species is rare in most regions in Japan, although the alien species is predominant now. Under the coexistence situation, it was observed whether the coexistence reduced the reproductive success of the native species.

This experiment was conducted in April 2009 at Osaka

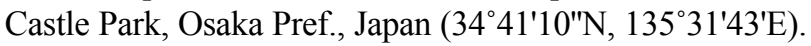
All flowers and fruits were removed with precision scissors before the experiment and buds were left. Fourteen pots, each with an individual of native $V$. p. lilacina were put in different patches of alien $V$. persica. Each patch of $V$. persica was $2 \mathrm{~m}$ or greater distant from other patches.
Seventeen other pots with an individual of native $V . p$. lilacina were left as controls at the laboratory yard where no alien $V$. persica had occurred. The distance between Osaka Castle Park and the laboratory yard was approximately $2.5 \mathrm{~km}$. Twenty days after transplanting, all pots in the park were moved to the laboratory yard again. All open flowers and buds were removed from transplanted and control individuals using precision scissors at that time. Fruits that derived from flowers that opened during the experimental period of 20 days remained. After another two weeks, all fruits were cropped and checked to ascertain whether they contained any seed or not. In this experiment, the seeds could not be counted because some fruits had dehisced and some seeds were lost during transplantation. A fruit with no seed was readily identifiable based on the fruit wall morphology (Figure 2), even after fruit dehiscence.

\subsection{Interspecific Pollination}

This experiment was undertaken to emphasize that interspecific pollination was the main cause of the decrease in the seed number in the native V. p. lilacina. In this experiment, the native flowers were artificially pollinated with mixed pollen of the conspecific and heterospecific pollens. Their seed numbers were compared

This experiment was conducted during 15-28 April 2010. Each newly opened flower of $V$. p. lilacina was assigned arbitrarily to either the treatment group (mixed pollination) or the control (conspecific pollination). For the treatment group, flowers were pollinated with conspecific pollens first and subsequently with heterospecific pollens. Procedures for the artificial pollination were identical to those in the auto-pollination experiment. The interval from the conspecific and the heterospecific pollination was less than $1 \mathrm{~min}$. For comparison, the same artificial pollination procedures were made for the alien $V$. persica. In the treatment of this experiment also, the flowers of $V$. persica were pollinated with conspecific pollens first and subsequently with those of $V$. p. lilacina as the treatment of the pollination with mixed pollen. The covering of individuals with fine mesh and fruits with

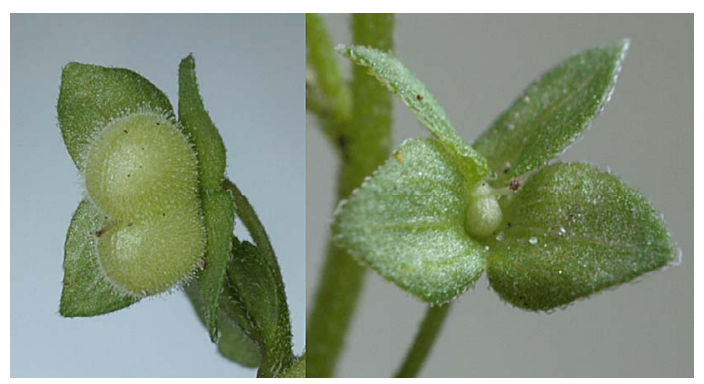

Figure 2. Morphologies of fruits containing some seeds (left) and no seed (right). 
paper was conducted exactly as in the auto-pollination experiment.

\subsection{Field Observation}

The coexistence of the native $V . p$. lilacina and the alien $V$. persica was not readily observed because the native species has remained rare on Honshu, the main island of Japan, to the present day. On some rural islands, however, the alien species is invading just now and the natives are maintained even today (Takakura, unpublished). On one such island, the author observed the effect of the coexistence with the alien $V$. persica on seed production of the native $V$. p. lilacina.

Observations were conducted on 5 April 2012 at NiiOhshima Island, Ehime Pref., Japan (33 $59^{\prime} 49^{\prime \prime} \mathrm{N}, 133^{\circ} 21^{\prime}$ 58 "E). The invasion of $V$. persica to this island seemed to have occurred in recent years because its distribution remains limited even today. The study site was hillside grassland at the southeastern part of the island at a small orchard on the top of the hill. The alien $V$. persica was predominant in the orchard; V. p. lilacina was predominant in the grassland area on the hillside. In a patch that consisted of approx. 50 individuals of $V$. p. lilacina, only one individual of $V$. persica was found. If the interspecific pollen transfer from the alien to surrounding native individuals decreased the seed production of the native $V$. p. lilacina, then the native individuals closer to the alien individual were expected to suffer a greater decrease of seed production. To test this hypothesis, the number of seeds that each native individual produced and the distance from the alien individual to each native individual were recorded. Fruits that did not dehisce but which still developed sufficiently were collected to count seeds in them for all native individuals within a $4 \mathrm{~m}$ radius from the alien individual. The distances from the alien individual were measured in centimeters using a tape measure. The collected fruits were brought to the laboratory and dissected to count the seeds.

\subsection{Statistical Analyses}

The aims and data structures were similar among the autopollination, transplanting experiment, the artificial pollination experiment, and the field observation. The response variables were the numbers of seeds per fruit or the fruiting success, whether each fruit contained any seeds or not. The number/weight of seeds produced might be related with the clustering structure, i.e. plant individual, because each individual produced two or more fruits. Thus, each statistical model had a random effect representing the inter-individual variance. When the seed number was the response variable, the error structures were assumed as Poisson distributions. In analyses for the fruiting success, the error structures were assumed as binomial distributions. Factors were the treatment of the transplanting in the transplanting experiments and the pollination treatment, respectively, in the auto-specific and interspecific pollination experiments. For data related to field observations, the independent variable was the distance from the alien individual to each native individual. In all analyses, the individual that produced fruits was regarded as a random effect. Generalized linear mixed models (GLMMs) [26] were applied. All analyses were conducted using software [27].

\section{Results}

\subsection{Auto-Pollination and Self-Compatibility}

In both V. p. lilacina and V. persica, even fruits of the auto-pollinated group produced as many seeds as those of the cross-pollinated group (Figure 3). In V. p. lilacina, the numbers of seeds per fruit were $11.8 \pm 0.38$ (mean \pm se) and 12.2 \pm 0.32 , respectively, in the auto-pollinated and cross-pollinated groups. In V. persica, they were $13.1 \pm 0.81$ (mean $\pm \mathrm{se}$ ) and $12.4 \pm 0.32$, respectively, in the auto-pollination and cross-pollination groups. In both species, the seed numbers per fruits were not significantly different between groups (GLMMs, $p>0.05)$.

\subsection{Transplanting Experiment}

The fruiting success (fruiting probability) was 0.49 in the individuals that were transplanted in patches of $V$. persica and 0.86 in the control (Figure 4). The effect of the transplanting on the fruiting success was significant (GLMM, estimate $\pm \mathrm{se}=-2.02 \pm 0.42, Z=-4.84, p<0.001)$.

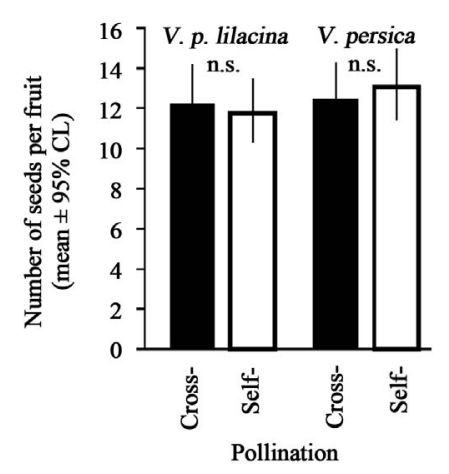

Figure 3. Seed numbers per fruit produced by cross-pollination (filled bar) and auto-pollination (open bar) in $V . p$. lilacina (left) and $V$. persica (right). Error bars represent 95\% confidence interval estimated under the assumption that the error structure depends on Poisson distributions. The symbol represents the statistical significance (GLMMs; ns, $p$ > 0.05). 


\subsection{Interspecific Pollination Experiment}

Pollination with mixed pollens decreased the number of seeds per fruit in the native $V . p$. lilacina. The number of seeds per fruit was $6.70 \pm 0.60$ (mean \pm se) in the treated (pollinated with mixed-pollen) group and $9.89 \pm 0.42$ in control (Figure 5). The effect of the mixed-pollen on the number of seeds was significant (GLMM, estimate $\pm \mathrm{se}=$ $-0.37 \pm 0.08, \mathrm{Z}=-5.00, p<0.001)$. In this experiment, only four fruits with no seeds were observed in the treated group. The fruiting success was 0.92 in the treatment group and 1.0 in control. The effect of the treatment on the fruiting success was not statistically significant (GLMM, $p>0.05$ ).

For the alien $V$. persica, however, the effect of the pollination with the mixed-pollen was not obvious (Figure 5). The number of seeds per fruit was $10.45 \pm 0.37$ (mean \pm se) in the treated (mixed-pollen) group and less than that in the control $(11.18 \pm 0.25)$. The difference was not significant (GLMM, $p>0.05$ ). All fruits contained seeds:

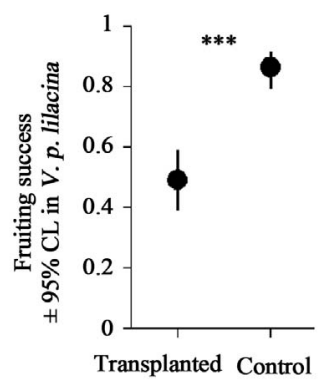

Figure 4. Fruiting successes of transplanted and control individuals of $V$. p. lilacina. Error bars represent a 95\% confidence interval estimated under the assumption that the error structure depends on binomial distributions. The symbol represents the statistical significance (GLMMs; ***: $p<$ 0.001; ns: $p>0.05$ ).

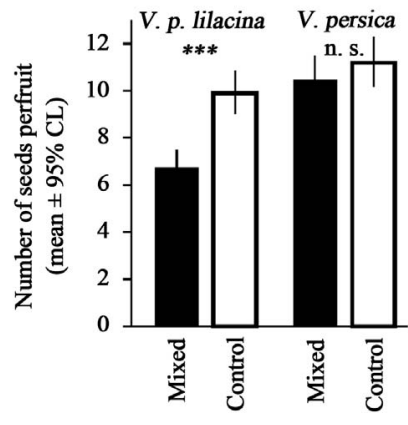

Figure 5. Seed numbers per fruit produced by the mixedpollination (filled bar) and the intraspecific pollination (open bar) in V. p. lilacina (left) and V. persica (right). Error bars represent $95 \%$ confidence interval estimated under the assumption that the error structure depends on Poisson distributions. Symbols indicate the statistical significance (GLMMs; ***: $p<0.001$; ns: $p>0.05$ ). the fruiting success was 1.0 in both groups.

\subsection{Field Observation}

With shorter distance from individuals to the alien $V$. persica, $V$. p. lilacina produced more empty fruits and less seed (Figure 6). For $V$. p. lilacina, individuals within $1 \mathrm{~m}$ radius from the alien $V$. persica individual, the fruiting success particularly was less than 0.5 for most individuals and the seeds per fruit were fewer than 5 for all individuals, whereas the fruiting success of 0.8 or higher and the seed numbers of 10 and more were achieved by individuals more than $1 \mathrm{~m}$ distant from the alien individual. Results of statistical analyses supported these tendencies; the coefficients of the distance from the alien individual were significantly positive for both the fruiting success (GLMM, estimate $\pm \mathrm{se}=3.51 \pm 0.90, Z=3.91, p<$ $0.001)$ and the number of seeds (GLMM, estimate $\pm \mathrm{se}=$ $0.85 \pm 0.13, Z=6.40, p<0.001)$. The alien $V$. persica individual had five fruits, none of which contained seed: the fruiting success of the $V$. persica individual was zero.

\section{Discussion}

This study demonstrated that both the native V. p. lilacina and the alien $V$. persica were able to produce seeds without pollination by any external pollen (Figure 3), which indicated that these species had a certain mechanism for auto-pollination and that they are selfcompatible. This result rejected the absence or shortage

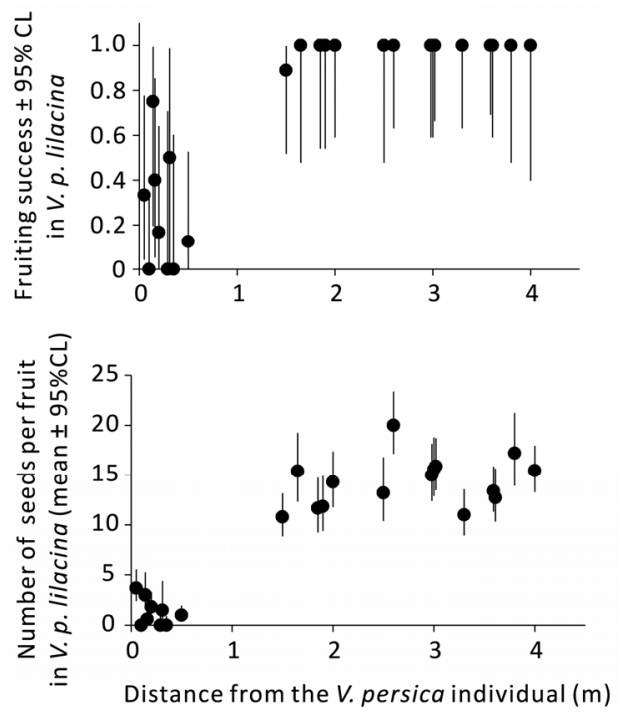

Figure 6. Relations between the fruiting success (top)/the number of seeds (bottom) in $V$. p. lilacina and the distance from the $V$. persica individual. Each plot shows data for an individual of $V$. p. lilacina. Error bars represent 95\% confidence intervals estimated under the assumption that the error structure depends on binomial (top) and Poisson (bottom) distributions. 
of the conspecific pollen as a reason for the decrease in seed production shown below. Subsequently, results demonstrated that the native $V$. p. lilacina underwent a decrease of the reproductive success by the coexistence with the alien $V$. persica in the transplanting experiment (Figure 4). This result strongly suggested that the effect of alien species was above ground, including the interspecific pollination, because native species were potted and their roots were physically isolated from the roots of alien species. This was also supported by the artificial pollination experiments (Figure 5). Furthermore, such an adverse interspecific effect actually occurred under natural conditions in the front line of the invasion (Figure 6). The artificial pollination experiment also showed that the effect is not even but rather one-way from the alien to the native species. However, when only one individual of the alien species intruded into the patch of the native species, the alien also produced no seed. These facts showed that the native species can also slightly exert a reproductive interference to the congeneric alien species.

These results suggest a scenario that the congeneric two species experienced during the last hundred years in Japan. Before the intrusion of the alien $V$. persica into Japan, the native $V . p$. lilacina was a common weed, as Makino $[19,20]$ described. In some regions like the study site of the field observation in this study, that is true even today. However, this situation probably changed after the intrusion and establishment of the alien species in Japan. Because the reproductive interference was almost entirely one-way, the replacement of the native by the alien species must have been steady, but not rapid because the alien species also suffers the slight effect of the resistive reproductive interference from the native species. Therefore, the extremely small numbers of the intruders must have prevented their reproduction in the patch of the native species, as shown in the field observation in this study. Dispersal with a long distance by a small number of individuals is crucially important for the rapid expansion of the distribution range of a species, even if the frequency is quite low [28,29]. For the alien $V$. persica, which was not capable of such a range expansion by a minority of intruders, it was probably necessary to expand its distribution from the periphery. Consequently, in some locations, other common alien weeds intrude but $V$. persica has not (Takakura peorsonal obs.).

The slight effect of the resistive reproductive interfereence, from native to alien species, might play an important role in the range expansion process of the alien species. However, it might be difficult to detect such a slight effect. The coexistence of the alien and native species is generally rare if the alien species is invasive. In such circumstances, the slight effect of the resistive reproductive interference that affects the alien species must be weakened because the reproductive interference works frequency-dependently and the native species is less dominant today. Additionally, even the experiment can fail to detect such a slight effect. In the present study also, the artificial pollination experiment represents an extremely slight decrease of the seed number in the mixedpollination group of the alien species (Figure 5). However, the decrement was quite small and not statistically significant. Even such a small effect was detected in field observations. An alien individual intruding into the patch of the native species would be unable to produce seed. These facts suggest the potency of the experimental transplantation of the small number of alien species to the native patch as a detection technique of slightly resistive reproductive interference. Nevertheless, this technique entails the severe risk of engendering further range expansion of the alien species. Development of more polished and less risky techniques remains as an issue for future research.

Results of this study demonstrated that individuals of $V$. p. lilacina and $V$. persica in the heterospecific patches suffered a decrease in reproductive success, fruiting success, and the number of seeds. However, the auto-pollination experiment demonstrated that flowers of Veronica species pollinated automatically with their own pollen and produced as many as cross-pollinated flowers. These facts indicate that the cause of the decrease in the reproductive success was not the shortage of the conspecific pollen but the presence of the heterospecific pollen. Reports of previous studies show that a native dandelion species suffers reproductive interference from the alien congeneric species $[8,9]$. The recipient species, Taraxacum japonicum, has been known to be self-incompatible [30]. In such self-incompatible species, the seed production decrease must be regarded as resulting from pollen limitation[18]. In self-compatible species such as Veronica, however, the shortage of conspecific pollens can not be the cause of the decrease in the seed production because sufficient pollen exists in the flower to fertilize all of its own ovules. For these reasons, the interspecific interaction in Veronica species described in this paper is a good case exemplifying the difference between the pollen limitation and the reproductive interference.

This study did not examine what animals served as pollinators in the field. Dipterans were sometimes observed visiting Veronica flowers during this study but there are no quantitative data. Knowledge of the pollination ecology of Veronica has remained limited $[31,32]$. Studies must be conducted to elucidate the pollinator fauna that transfer pollen and which catalyze the reproductive interference in Veronica species.

\section{Acknowledgements}

I deeply thank Dr. Taro Seki for his guidance in my field 
work. This work was partly supported by a grant from the Sumitomo Foundation and a Grant-in-Aid for Young Scientists (B, No. 22710240) from the Ministry of Education, Culture, Sports, Science and Technology, Japan.

\section{REFERENCES}

[1] J. T. A. Dick, R. W. Elwood and D. E. Irvine, "Displacement of the Native Irish Freshwater Amphipod Gammarus duebeni by the Introduced G. pulex," Irish Naturalists' Journal, Vol. 23, No. 8, 1990, pp. 313-316.

[2] J. H. Hobbs, E. A. Hughes and B. H. Eichold II, "Replacement of Aedes aegypti by Aedes albopictus in Mobile, Alabama," Journal of the American Mosquito Control Association, Vol. 7, No. 3, 1991, pp. 488-489.

[3] A. M. Hill and D. M. Lodge, "Replacement of Resident Crayfishes by an Exotic Crayfish: The Roles of Competition and Predation," Ecological Applications, Vol. 9, No. 2, 1999, pp. 678-690. doi:10.1890/1051-0761(1999)009[0678:RORCBA]2.0.C $\underline{\mathrm{O} ; 2}$

[4] P. E. Weihe and R. K. Neely, "The Effects of Shading on Competition between Purple Loosestrife and BroadLeaved Cattail," Aquatic Botany, Vol. 59, No. 1-2, 1997 , pp. 127-138. doi:10.1016/S0304-3770(97)00023-5

[5] D. Chmura and E. Sierka, "The Invasibility of Deciduous Forest Communities after Disturbance: A Case Study of Carex brizoides and Impatiens parviflora invasion," Forest Ecology and Management, Vol. 242, No. 2-3, 2007, pp. 487- 495.

[6] M. Hejda, P. Pyšek and V. Jarošík, "Impact of Invasive Plants on the Species Richness, Diversity and Composition of Invaded Communities," Journal of Ecology, Vol. 97, No. 3, 2009, pp. 393-403. doi:10.1111/j.1365-2745.2009.01480.x

[7] A. D'Amore, E. Kirby and V. Hemingway, "Reproductive Interference by an Invasive Species: An Evolutionary Trap?" Herpetological Conservation and Biology, Vol. 4, No. 3, 2009, pp. 325-330.

[8] K. I. Takakura, T. Nishida, T. Matsumoto and S. Nishida, "Alien Dandelion Reduces the Seed Set of a Native Congener through Frequency-Dependent and One-Sided Effects," Biological Invasions, Vol. 11, No. 4, 2009, pp. 973981. doi:10.1007/s10530-008-9309-Z

[9] K. I. Takakura and S. Fujii, "Reproductive Interference and Salinity Tolerance Differentiate Habitat Use between Two Alien Cockleburs: Xanthium occidentale and $X$. italicum (Compositae)," Plant Ecology, Vol. 206, No. 2, 2010, pp. 309-319. doi:10.1007/s11258-009-9644-x

[10] M. B. S. Char, "Pollen Allelopathy," Naturwissenschaften, Vol. 64, No. 9, 1977, pp. 489-490. doi:10.1007/BF00446271

[11] S. D. Murphy and L. W. Aarssen, "Reduced Seed Set in Elytrigia repens Caused by Allelopathic Pollen from Phleum pratense," Canadian Journal of Botany, Vol. 73, No. 9, 1995, pp. 1417-1422. doi:10.1139/b95-154

[12] T. Matsumoto, K. I. Takakura and T. Nishida, "Alien
Pollen Grains Interfere with the Reproductive Success of Native Congener," Biological Invasions, Vol. 12, No. 6, 2010, pp. 1617-1626. doi:10.1007/s10530-009-9574-5

[13] E. Kuno, "Competitive Exclusion through Reproductive Interference," Research on Population Ecology, Vol. 34, No. 2, 1992, pp. 275-284. doi:10.1007/BF02514797

[14] T. Ben-David, U. Gerson and S. Morin, "Asymmetric Reproductive Interference between Two Closely Related Spider Mites: Tetranychus urticae and T. turkestani (Acari: Tetranychidae)," Experimental Applied Acarology, Vol. 48, No. 3, 2009, pp. 213-227. doi:10.1007/s10493-008-9228-9

[15] D. W. Crowder, M. I. Sitvarin and Y. Carrière, "Plasticity in Mating Behaviour Drives Asymmetric Reproductive Interference in Whiteflies," Animal Behaviour, Vol. 79 , No. 3, 2010, pp. 579-587. doi:10.1016/j.anbehav.2009.11.025

[16] S. Noriyuki, N. Osawa and T. Nishida, "Asymmetric Reproductive Interference between Specialist and Generalist Predatory Ladybirds," Journal of Animal Ecology, Vol. 81, No. 5, 2012, pp. 1077-1085. doi:10.1111/j.1365-2656.2012.01984.x

[17] R. B. Runquist and M. L. Stanton, "Asymmetric and Frequency-Dependent Pollinator-Mediated Interactions May Influence Competitive Displacement in Two Vernal Pool Plants," Ecology Letters, Vol. 16, No. 2, 2013, pp. 183190. doi:10.1111/ele.12026

[18] I. Kandori, T. Hirao, S. Matsunaga and T. Kurosaki, "An Invasive Dandelion Unilaterally Reduces the Reproduction of a Native Congener through Competition for Pollination," Oecologia, Vol. 159, No. 3, 2009, pp. 559-569. doi:10.1007/s00442-008-1250-4

[19] T. Makino, "Researches on Wild Plants," Sanbunsha, Tokyo, 1907.

[20] T. Makino, "Makino’s Illustrated Flora of Japan,” Hokuryukan, Tokyo, 1940.

[21] R. Miura, R. Doi and M. Yoshino, "Distribution and Myrmecochory of Veronica polita subsp. lilacina Observed in the Area around Kyoto University," Journal of Weed Science and Technology, Vol. 48, No. 3, 2003, pp. 140-143. doi: $10.3719 /$ weed.48.140

[22] T. Makino, "Danshi-Henyo Sono-Kyu (An Essay of Plants 9)," Journal of Japanese Botany, Vol. 2, No. 3, 1919, pp. 61-66.

[23] Environment Agency of Japan, "Threatened Wildlife of Japan: Red Data Book," 2nd Edition, Wildlife Research Center, Tokyo, 2000.

[24] S. G. Shetler and S. K. Wiser, "First Flowering Dates for Spring-Blooming Plants of the Washington DC, Area for the Years 1970 to 1983," Proceedings of the Biological Society of Washington, Vol. 100, No. 4, pp. 993-1017.

[25] K. Yamazaki, "Scrophulariaceae," In: Y. Satake, T. Ooi, S. Kitamura, T. Watari and T. Tominari, Eds., Wild Flowers of Japan III, Heibonsha, Tokyo, 1981, pp. 97-121.

[26] B. M. Bolker, M. E. Brooks, C. J. Clark, S. W. Geange, J. R. Poulsen, M. H. Stevens and J. S. White, "Generalized Linear Mixedmodels: A Practical Guide for Ecology and 
Evolution," Trends in Ecology and Evolution, Vol. 24, No. 3, 2009, pp. 127-135. doi:10.1016/j.tree.2008.10.008

[27] R Core Team, "R: A Language and Environment for Statistical Computing," R Foundation for Statistical Computing, Vienna, 2012.

[28] N. Shigesada and K. Kawasaki, "Biological Invasions: Theory and Practice," Oxford University Press, Oxford, 1997.

[29] S. I. Higgins and D. M. Richardson, "Predicting Plant Migration Rates in a Changing World: The Role of LongDistance Dispersal," The American Naturalist, Vol. 153,
No. 5, 1990, pp. 464-475. doi:10.1086/303193

[30] A. J. Richards, "The Origin of Taraxacum Agamospecies," Botanical Journal of the Linnean Society, Vol. 66, No. 3, 1973, pp. 189-211. doi:10.1111/j.1095-8339.1973.tb02169.x

[31] E. M. Heine, "Observations on the Pollination of New Zealand Flowering Plants," Transactions of the Royal Society of New Zealand, Vol. 67, No. 2, 1937, pp. 133-148.

[32] D. J. Goyder, "Pollination Ecology of Five Species in a Limestone Community," Wasonia, Vol. 14, No. 4, 1983, pp. 397-405. 